\title{
A MODIFIED STANDARDIZED METHOD TO EXTRACT AND STORE INSECT HEMOLYMPH WITH USE OF A GLASS CAPILLARY
}

\author{
Paweł Migdał* \\ Agnieszka Murawska \\ Adam Roman \\ Wrocław University of Environmental and Life Sciences, Wrocław, Poland \\ *corresponding author: pawel.migdal@upwr.edu.pl \\ Received: 31 July 2019; accepted 20 January 2020
}

A b s t ract

Hemolymph is the "blood" circulating in the entire insect body. Analysis of this fluid gives information about the condition of the insect. The most precise analyses are conducted on insects' hemolymph suspended in $0.6 \%$ physiological saline ( $\mathrm{NaCl}$ ). Most current hemolymph extraction methods are either difficult or do not provide pure material, the contamination of collected insect "blood" can change results. This study aimed to develop a technique for extract hemolymph, both easy and without risk of contaminating derived material. The presented method is a modification of available ways to extract, store and transport hemolymph with the use of a glass capillary. For the development of this technique, adult worker honey bees (Apis mellifera $\mathrm{L}$.) were used. The method required such basic equipment as a glass capillary, sterile tweezer, Eppendorf tube and physiological saline. The collected hemolymph were frozen and hence sent in a glass capillary to another laboratory for analysis.

Keywords: hemolymph, honey bee, insect, transporting hemolymph

\section{INTRODUCTION}

Hemolymph is the circulating fluid of arthropods abd analogous to the blood in vertebrates (Wyatt, 1961). Analysis of the hemolymph proteins provides significant physiological and immune system data and reflects the condition of the insect organism (Bogaerts et al., 2009; Levy, Bulet \& Ehret-Sabatier, 2004). The literature contains many methods for hemolymph extraction. The most precise analyses are carried out on the insect hemolymph suspended in $0.6 \%$ physiological saline $(\mathrm{NaCl})$. The most frequent method is puncturing the dorsal sinus of the thorax and collecting hemolymph straight to the capillary. The collected material is free from microbiological contamination, but this technique is relatively difficult because puncturing the dorsal sinus of the thorax requires precision due to the risk of intestine perforation (Łoś \& Strachecka, 2018). The much easier practice is to extract hemolymph after detaching the antennae and then to collect leaked fluid with a pipette (Mayack \& Naug, 2010; Borsuk et al., 2017). However, this method requires the disinfection of the area around the bee's antennae (Borsuk et al., 2017), otherwise, it carries a risk of microbiological contamination of the hemolymph (Borsuk et al., 2017, Łoś \& Strachecka, 2018). This study aimed to develop a technique for hemolymph extraction, both easy and with reduced risk of microbiological contamination by derived material, based on current methods.

\section{MATERIAL AND METHODS}

For a presentation of the modified method of hemolymph extraction, adult worker honey bees ( $A$. mellifera $L$.) in the age of 2-days old, 15-days old and over 21-days old were used. Before the collection of hemolymph, bees had access to sugar syrup $\left(1 \mathrm{~mol} / \mathrm{dm}^{3}\right)$. The insect was placed on a styrofoam stand and slightly pressed on its thorax with the index finger to prevent the it from moving. Then the bee's antenna was removed using sterile tweezers (Fig. 1). Next, the glass capillary (e.g., $20 \mu$ l; "endto-end" type; without anticoagulant) was taken and placed in the spot of the removed antenna. 
Table 1.

Characterization of the modified method of collecting hemolymph compared to methods presented in the publication by Łoś \& Strachecka (2018)

\begin{tabular}{|c|c|c|c|c|}
\hline $\begin{array}{l}\text { hemolymph } \\
\text { outflow }\end{array}$ & $\begin{array}{c}\text { After } \\
\text { detachment of } \\
\text { antennae }\end{array}$ & $\begin{array}{c}\text { After incision } \\
\text { of body with a } \\
\text { scalpel }\end{array}$ & $\begin{array}{c}\text { into a glass } \\
\text { capillary by } \\
\text { puncturing body }\end{array}$ & $\begin{array}{c}\text { After } \\
\text { detachment of } \\
\text { antennae with } \\
\text { glass capillary } \\
\text { (modified } \\
\text { method) }\end{array}$ \\
\hline Difficulty level & easy & difficult & $\begin{array}{l}\text { difficult and } \\
\text { requiring } \\
\text { precision }\end{array}$ & easy \\
\hline $\begin{array}{l}\text { Microbiological } \\
\text { contamination } \\
\text { of collected } \\
\text { material }\end{array}$ & likely & very likely & unlikely & unlikely \\
\hline Transport & very difficult & very difficult & difficult & easy \\
\hline $\begin{array}{l}\text { Approximate } \\
\text { amount of } \\
\text { collected } \\
\text { material }\end{array}$ & $5-10 \mu \mathrm{L}$ & 2-8 & $6-20 \mu \mathrm{L}$ & 8-20 \\
\hline $\begin{array}{c}\text { Stage of } \\
\text { insects used } \\
\text { for hemolymph } \\
\text { extraction }\end{array}$ & adult & adult and larvae & $\begin{array}{l}\text { adult with } \\
\text { developed circu- } \\
\text { latory system }\end{array}$ & adult \\
\hline $\begin{array}{l}\text { Storage of } \\
\text { collected } \\
\text { material }\end{array}$ & difficult & difficult & easy & easy \\
\hline $\begin{array}{l}\text { Collecting } \\
\text { efficiency }\end{array}$ & fast & slow & slow & fast \\
\hline $\begin{array}{c}\text { Possibility of } \\
\text { hemocytes } \\
\text { adhesion }\end{array}$ & no & no & yes & yes \\
\hline
\end{tabular}

Simultaneously the bee's abdomen was gently pressed to increase the hemolymph pressure. Pure hemolymph was collected straight from the hole after antenna removal to the glass capillary. The capillary with hemolymph was then put into an Eppendorf tube $1.5 \mathrm{ml}$ with $150 \mu \mathrm{l}$ of $0.6 \%$ $\mathrm{NaCl}$ and next closed and put on dry ice (only if the transport of the hemolymph to the another laboratory is necessary). The extraction process was conducted over ice blocks to prevent melanization of collected material. Finally, the samples were stored in cryo boxes at $-80^{\circ} \mathrm{C}$.

\section{RESULTS}

Hemolymph collection is one of the most important activities during biochemical analyses of insects (Garrido et al., 2013). It is most often 


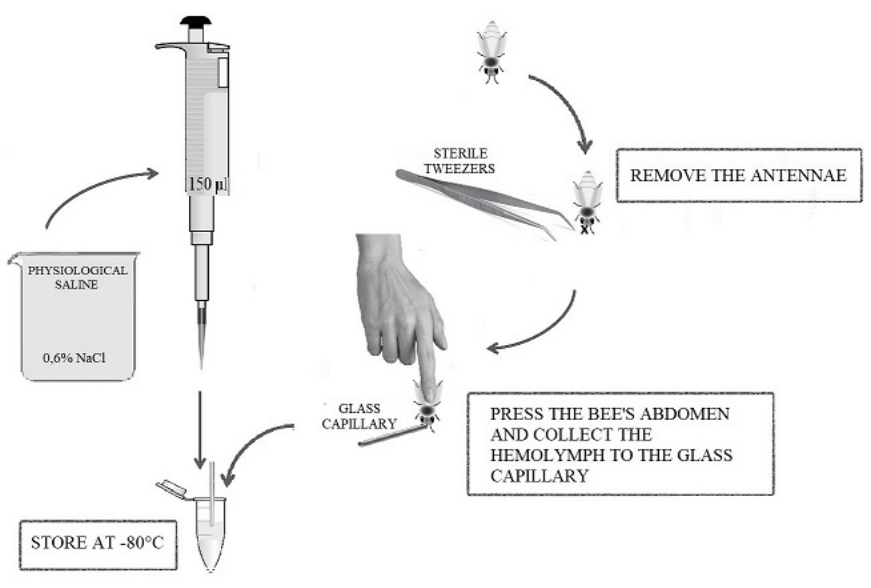

Fig. 1. The scheme of the modified technique of collecting hemolymph flowing out after detachment of the antennae with use of a glass capillary.

performed with capillaries while puncturing the heart, the dorsal or ventral thorax sinus, or the dorsal aorta (Chan et al., 2006; Garrido et al., 2013). The method of hemolymph extraction should be simple, provide microbiological safety of obtained material and make storage possible (Borsuk et al., 2017).

None of the current methods meets all these requirements. The most common problem during hemolymph extraction is its melanization, and then storage and transport of the collected material. The unintentional changes in the hemolymph can influence the analysis and reliability of the results. The modified technique allows pure hemolymph to be extracted easily with the use of a glass capillary. Hemolymph is then stored and frozen in a glass capillary at $-80^{\circ} \mathrm{C}$ up to twelve months. The insect "blood" can be then transported inside a glass capillary in a safe environment for a long distance.

In this research, $50 \%$ of hemolymph samples were transported $600 \mathrm{~km}$ for twenty-four hours in dry ice distance for analysis. The remaining $50 \%$ of the samples were analyzed immediately after collection. The results from the analysis of samples after transport were similar to those samples, which were analyzed immediately after collection. A glass capillary ensures also higher microbiological safety than pipette tips because researcher' movements are more precise. In addition, the amount of obtained fluid in a modified method is relatively large (Tab. 1). With this fast and easy method hemolymph is extracted from one honey bee individual in only thirty seconds and from a glass capillary only fifteen seconds. During this research, 2158 worker bees were used and 2000 (93\%) successful hemolymph extractions were performed .

\section{CONCLUSIONS}

Improved methods can be useful in the research on insects, especially pollinators. The presented method is meant for the quick collection of hemolymph to a glass capillary. Furthermore, the proposed way is easier than previous methods and give the possibility for transport hemolymph between laboratories in 24h. For contemporary research is necessary to make biochemical analysis in order to better understanding the functioning of insects' organisms.

\section{REFERENCES}

Bogaerts, A., Baggerman, G., Vierstraete, E., Schoofs, L., Verleyen, P. (2009). The hemolymph proteome of the honeybee: gel-based or gel-free? Proteomics, 911), 3201-3208. https://doi.org/10.1002/ pmic.200800604

Borsuk, G., Ptaszyńska, A., A., Olszewski, K., Domaciuk, M., Krutmuang, P., Paleolog, J. (2017). A New Method for Quick and Easy Hemolymph Collection from Apidae Adults. PLoS ONE, 12(1). https://doi.org/10.1371/ journal.pone.0170487

Chan, Q.W., Howes, C.G., \& Foster, L.J. (2006). Quantitative comparison of caste differences in honeybee hemolymph. Molecular \& Cellular Proteomics. 5, 2252-2262. pmid:16920818

Garrido, M.P., Martin, M.L., Negri, P., Martin, E.J. (2013). A standardized method to extract and store hemolymph from Apis mellifera and the ectoparasites Varroa destructor from protein analysis. Journal of Apicultural Research, 52(2), 67-68. https://doi. 


\section{— MGDHA ET HL. _ Modified method for collecting insect hemolymph}

org/10.3896/IBRA.1.52.2.13

Levy, F., Bulet, P., \& Ehret-Sabatier, L. (2004). Proteomic analysis of the systemic immune response of Drosophila. Molecular\& Cellular Proteomics, 3(2), 156-166. https://doi.org/10.1074/mcp.M300114MCP200

Łoś, A., \& Strachecka A. (2018). Fast and Cost-Effective Biochemical Spectrophotometric Analysis of Solution of Insect "Blood" and Body Surface Elution. Sensors, 18(5), 1494. https://doi.org/10.3390/ s18051494
Mayack, C., \& Naug, D. (2010). Parasitic infection leads to decline in hemolymph sugar levels in honeybee foragers. Journal of Insect Physiology, 56, 1572 1575. pmid:20685210

Wyatt, G.R. (1961). The Biochemistry of Insect Hemolymph. Annual Review of Entomology, 6, 75-102. https://doi.org/10.1146/annurev. en.06.010161.000451 